\title{
Rethinking Docent Training at the Montreal Museum of Fine Arts: A Pilot Project
}

\author{
Richard Lachapelle (Concordia University), and Emily Keenlyside (Concordia University), \\ Manon Douesnard. (Independent Consultant) \\ richard.lachapelle@concordia.ca, ekeenlyside@gmail.com, manondouesnard@gmail.com
}

\begin{abstract}
In 2014-2015, the Montreal Museum of Fine Arts (MMFA) and Concordia University's School of Extended Learning conducted a joint pilot project with the objective of determining the effectiveness of a new approach for training volunteer museum guides based on a dialogic method. In this paper, we address: (i) the conceptualization of alternative training based on dialogic concepts; (ii) the development of a new course outline; (iii) the trial period during which volunteers took part in test training; (iv) and, finally, aspects of what we learned during this undertaking. This pilot project is important because it will influence future docent training at the MMFA and possibly elsewhere.
\end{abstract}

Keywords: Museum education; docent training; dialogic teaching; video elicitation; participantcentered exchanges.

$\mathrm{n}$ this paper, we report on a pilot research project conducted in 2014-2015 by the Montreal
Museum of Fine Arts (MMFA) in conjunction with Concordia University's School of
Extended Learning. The objective of the project was to determine whether or not a new skills-based training course, founded largely on a dialogic approach, would prove successful as a foundation course in the training of a new generation of volunteer museum guides (docents). The authors will address each stage in the investigative process as it unfolded: (i) the initial conceptualization of an alternative approach in training based on dialogic concepts; (ii) the development of a new course outline and new course content under the leadership of professional museum educators; (iii) the trial period during which a carefully selected cohort of volunteers took part in the test training; (iv) finally, the results of the pilot project based on data collected from all constituents (the pilot project participants, the professional course instructors, the museum and university personnel). The MMFA is an acknowledged leader in fine art museum 
education in Canada. Therefore, this pilot research and any related future developments have the potential to influence standards of docents training in both in Canada and in North America.

\section{The context: Docent training at the Montreal Museum of Fine Arts}

In previous decades, docent training at the Montreal Museum of Fine Arts consisted of the sequential completion of three distinct components. Adults wishing to be considered as candidates for a volunteer position as a docent at the Museum had to first complete a continuing education course offered at Concordia University. This introductory course offered candidates a foundation in art history and basic training in teaching methods. Upon successful completion of this course, candidates were considered qualified to apply to the Museum for possible acceptance into the MMFA docent-training program. If accepted into the program, candidate docents were then required to complete an additional year of training offered by the Museum itself.

In late 2013, the Museum's Education Division called into question this time-honoured approach to docent training: it suspected that an education-centered approach might be more effective as a method for training new docents. Therefore, in January 2014, the museum struck a joint MMFA/Concordia University committee in order to study and propose a new course design for the first component of a revitalized docent-training program. The steering committee ${ }^{\mathrm{ii}}$ eventually decided to conduct a pilot project in which it would examine whether docents can be successfully trained to use a dialogic approach as the preferred method for conducting guided tours in the museum.

Several social scientists and educators are conducting and publishing ongoing research on dialogic education as a contemporary model for guiding the practice of teaching and learning (Burnham \& Kai-Kee, 2011; Elbers \& De Haan, 2004; Flecha, 2000; Flecha \& Soler, 2013; Frijters \& Dam, 2008; Plaza, 2010; Renshaw, 2004; Wegerif, 2006). According to Burnham and 
Kai-Kee (2011), the dialogic approach seeks to encourage verbal exchanges among visitors (related to the works of art in an exhibition) by resorting to informal conversation in combination with structured discussions (pp. 79-92). The idea that learning can be fostered through dialogue has a long and distinguished history that can be traced all the way back to Socrates (Renshaw, 2004, p.1). However, both Renshaw (2004) and Plaza (2010) emphasize that recent psychological, sociological, cultural, and educational research has conferred an ongoing relevance to this educational theory. In addition, Plaza (2010) makes the following key points about dialogic learning as an educational approach: (i) dialogic learning depends on social interaction among learners for the purposes of meaning making; and (ii) language is the means through which this interactive construction of meaning becomes possible (p. 61). For the purposes of our pilot project, we chose Burnham \& Kai-Kee's work (2011) to guide our activities since these educators discuss dialogic learning specifically as it occurs in the context of the fine art museum.

In order to conduct the pilot project, two professional educators ${ }^{\mathrm{iii}}$ were hired to prepare (during the spring and summer of 2014) a course outline and teaching materials for the new course. Finally, during the fall of 2014, the same two educators conducted a pilot test of the new course with a first group of volunteer participants. One of the instructors brought her expertise related to social inclusion and accessibility, two decades as a museum educator, and previous experience facilitating community-based learning to the study. The second contributed expertise in the area of multisensory and physical engagement with works of art derived from her research into public art and 15 years of teaching art to various populations. Both instructors share a keen interest in engaged learning and reflective practice; they are both co-authors of this paper. 
A total of 20 students - three men and seventeen women between the ages of 50 and 70 - were selected to take part in the project. The first iteration of the new university course, CEVA 916 - Museum Guide Training for the Montreal Museum of Fine Arts, was offered as a pilot project during the fall 2014 semester. All course activities were offered at the MMFA. As a comprehensive university course, it covered a wide array of thematic clusters (self-reflective practice, museum spaces, museum publics, aspects of aesthetics, and facilitation of group learning). It included readings, assignments, and evaluations. The primary learning objective of the course took the form of an end-of-term assignment, a 15-minute guided tour, or encounter ${ }^{\text {iv }}$, in which each student-docent engaged his or her peers with two works of art selected from one of the Museum's permanent collections.

\section{Privileging a Dialogic Model}

As anticipated by the steering committee members prior to the design of the course, we frequently witnessed students falling back either on a transmission model or a "leading question" strategy during the student-docent led tours. In order to respond to an ongoing concern among students that facilitating a participant-driven exchange would dilute content, as instructors we needed to continually demonstrate its strengths and encourage students to reimagine what a guided visit could be: a dialogue-driven encounter, or meeting of minds comprising multiple voices. This approach reflected the philosophies shared by the MMFA and Concordia's CCE,

namely accessibility, openness to diversity, and engagement. ${ }^{\mathrm{v}}$ Therefore, the goal driving both the structure and content of the course was that the skills and related theory acquired throughout the training should equip students with effective facilitation and questioning strategies. These strategies, combined with an increased sensitivity and respect for the range of possible responses and experiences on the part of participants, would enable student docents to both offer and elicit 
formal and contextual information in ways that were both object- and participant-centered. Thus, the thrust of this skills-based training was experiential, reinforcing both the how and the why of dialogue in art museums.

Learning activities were informed by our own teaching experience as well as the past decade of literature that explores social learning and visitor engagement. We understand dialogue within the spectrum of what Burnham and Kai-Kee (2011) refer to as distinct gallery teaching modes: conversation, discussion, and dialogue — the latter being situated at the midpoint of this trio, sharing "the open, improvisatory quality of conversation, but...imbued from the outset with a stronger sense of purpose" (p. 86). As the authors suggest, "Talking is not in itself our objective...but a means of giving access to profound and prolonged experiences with works of art. What we seek is a certain kind and quality of talk: talk that yields knowledge and understanding" (pp. 79-80). While dialogic learning was presented as the ideal mode for use with the general public, students also explored other interactive teaching modes, given that dialogue requires not only highly developed skills on the part of the facilitator, but a particular initiative on the part of participants that cannot be guaranteed from one group to the next. As the museum's orientation is increasingly grounded in the well-being and inclusion of diverse publics, Burnham and Kai-Kee's model offered a framework that allowed us to draw students docents' attention to the subtle distinctions between different approaches to group learning. It was hoped that, in understanding these differences as they relate to the roles of both guides and participants, students would eventually be able to determine the best circumstances under which to favour, or move between, the different teaching modes-conversation, dialogue, and discussion. For example, while a discussion may reflect a guide's own desire to cover particular material, it may also best serve participants who might hesitate, for various reasons, to 
participate actively without prompts. While a conversation may lack the rigour required for a group of graduate students, it may be the perfect informal introduction for a group of first-time visitors with little experience with visual art or art museums. As Burnham and Kai-Kee's model suggests, guides may also integrate multiple teaching modes within the same encounter; in our experience this could depend, for example, on particular artworks, subject matter, or participants' energy levels.

While Burnham and Kai-Kee doubt the value of questioning in gallery teaching (2011, pp. 94-111), we agree amongst ourselves and with others ${ }^{\mathrm{vi}}$ that when skilfully and conscientiously used, non-leading questions can open up new possibilities for creating meaning, understanding, and knowledge that can still remain focused on participants and the objects they are exploring together. That said, having witnessed seemingly forced use of questioning early on in this project, we wanted students to be cognizant that leading questions can be a frustrating experience for participants and that perceived coercion or inauthenticity can hinder connectionand thus learning - even more so than enthusiastic lecturing. In this context, the bulk of the method for encouraging dialogue (i.e. the how) was active listening, effective design and application of questions, drawing on the senses, and the use of a facilitator's approach to communicating key information about the artworks - that is, in response to key concepts and questions raised by museum visitors themselves. The reason for choosing dialogue over other approaches (i.e. the why) was to develop an understanding of how authentic and responsive interactions increase the probability of inclusion, active meaning making, and positive group learning among a wide range of potential participants.

In the sections that follow, the authors communicate their findings about the pilot study related to two specific areas: (i) the strengths of video elicitation for student-docent training and 
for evaluating student-docents' teaching; (ii) meeting the challenges related to teaching studentdocents the skills needed for dialogic gallery teaching.

\section{Video elicitation: Identifying the challenges of dialogic teaching}

Video elicitation. Of the various methods we used to train student-docents in using a dialogic approach for conducting guided tours, we have chosen to discuss video elicitation activities because of the effectiveness of this method in identifying the challenges of a dialogic approach and in verifying student engagement with course content.

Prior to this course, video recordings of the student-docents' guided tours were used by the Museum to evaluate students in a final pass/fail appraisal. In this pilot project, we decided to use video as a reflexive learning tool — a method referred to as video elicitation — instead of limiting its use for the sole purpose of the evaluation of student-docents. We also made the decision to produce video recordings of student-docents conducting guided tours at the mid-term point; this turned out to be a successful strategy for lowering students' stress related to the inevitable end-of-term evaluation. By using video recordings throughout the term, we also provided students with the time needed for addressing challenges in cases where students were experiencing difficulties.

Our expectations regarding students' performance at the mid-term videotaping were as follows: in a simulated guided tour, student-docents were to conduct an interactive and inclusive exchange; validate multiple and individual interpretations of the work of art; use visitors' ideas to advance the group's discussion; and, finally, use multiple engagement strategies such as multisensory approaches to the work of art.

Students took part in two separate video elicitation activities. For the first, students reviewed their respective videos with their peers and asked questions to each other using a 
predetermined list of possibilities we had devised for them. Following the peer-led exercise, a second one-on-one exchange with instructors prompted students to elicit information from the recordings about their performance as student-docents as we watched the videos a second time, reviewing the recording and pausing at points of particular interest.

An example of one such video shows a student-docent in the middle of a visit with the work of art-Morning, Lake Superior, a depiction of a winter landscape by the artist Lawren Harris (c. 1921). Around her, about a dozen of the student-docent's peers take on the role of pretend-visitors. At the start of the video, the student-docent in question uses conceptual and formal language to transmit information about the painting: "It is spiritual advancement, it is moral perfection, wisdom. And when you get to the white (color), it is, of course, purity, the final outcome" (author translation). But then, to our surprise, the student-docent transforms the visit from a lecture into a dialogue, with multiple pretend-visitors participating in a verbal exchange about the frozen landscape depicted in Harris' painting. The student-docent asks the pretendvisitors: "Could you imagine that there is sound? Imagine...close your eyes and imagine music. What would you see as music to animate this painting?" One of the pretend-visitors answers: "Cracks!" Not surprisingly, this is a comment to which quite a few of the students laugh. Considering the success of her previous comment with the group, the same pretend-visitor continues: "Just cracks because you have the impression that the ice is going to give!" The student-docent acknowledges: "Yes, the way is not easy!" Now, a second pretend-visitor contributes to what is becoming an exchange amongst several pretend-visitors: "When I find myself in such a location (pointing to the frozen landscape), I don't like music. I like the calm." A few more pretend-visitors join in, simultaneously saying: "I like silence". Another student contributes one last point of view to the exchange: "Divine music, repetitive. There are few 
notes...the kind of music that leads to meditation". The student-docent acknowledges: "Yes, quite right".

Identifying Potential Problems. Video elicitation activities were well suited for identifying both strengths and areas for improvement in the students' performances. The video footage used in these activities captured the reality of specific moments in student-docents' guided tours by providing a permanent record of key events captured in real-time. It was possible therefore to examine the timeline of an event and view important aspects of the event over and over again. The video recordings enabled students to identify and work on several challenges such as: unexpected visitor questions and comments, distractions, the unintentional and unmindful use of lecturing instead of dialogue, and problems with the timing of events.

Verifying the Effectiveness of the Multisensory Approach. Furthermore, we taught students to consider how the various senses contribute to an appreciation of works of visual art. We asked them to devise ways of using multisensory engagement strategies as a component in their guided visits. Video elicitation activities revealed the effectiveness of the multisensory activities that the student-docents developed in order to engage the other students. In the example presented earlier, the use of a simple question about the sounds connected to a painting transformed what began as a transmission-style lecture into a dynamic exchange among several students. A multisensory approach has a transversal character that promotes links to past personal sensorial experiences and the use of these experiences as building blocks for creating knowledge and meaning. Commenting on the use of multisensory approaches in dialogic learning, one student declared: "Nice discovery. I was stunned by all a work of art can reveal when we explore it with all of our senses, imagination, and memory". 


\section{Challenging assumptions about dialogic gallery teaching}

The use of myriad gallery activities that develop key skills in interpretation and facilitation allowed student-docents to experience art museum encounters from the perspective of both participant and guide. It was our assertion that reflecting on their own learning needs, viewing strategies, and questions would increase student-docents' respect for their future participants' needs, expectations, and potential. The following example is a simple activity that took student-docents from the research phase to the facilitation of a group experience with a work of art. This activity demonstrated, through direct experience, how an encounter facilitated by the same educator can vary both in content and distinct learning experiences while remaining focused on the object. Student-docents were reminded that their written scenario is a toolbox of information and questions; how and what they draw from it depends on the unique starting point and evolution of each encounter. We describe this particular activity because it demonstrates our teaching strategies by combining modelling with experiential learning. It also highlights a concrete response to the main challenge previously described: student-docents' ongoing concern that making room for multiple voices, using an approach in which visitors themselves determine the direction of the exchange, could possibly lead to overlooking important information about an artwork related either to art history or the artists' intentions.

The activity comprised two 10-minute encounters, both of which were facilitated by an instructor and observed by students. The selected work was I Learned the Hard Way by Mickalene Thomas, painted in 2010. This work offered multiple entry points as well as opportunities for sensory engagement: the role of the muse; unexpected surface qualities; family relationships; civil rights; popular culture; nostalgia; art historical references; and notions of beauty, among others. 
At the start of the workshop, the 20 students were divided into three teams-two groups of 'visitors' and one group of observers. For each encounter, they took note of 1) what information the student-guide transmitted and in what context; 2) his or her questions; and 3) the themes discussed. We followed up on the activity in class with a large group discussion, based on the observers' comparisons between the two groups' experiences.

This workshop emphasized the importance of being flexible and open to a variety of interpretations grounded in sustained looking and an open invitation to share, as well as how these interpretations allow for a dialogue to unfold. It demonstrated how the selection of openended, non-leading, and adapted questions can nourish the learning experience at crucial moments. It allowed students to observe - and again, experience first hand-how relevant facts and anecdotes we may have spent hours researching can be left out from one visit to the next, depending on their pertinence in the moment. The workshop also reminded students that not all participants choose to contribute in the same way. Furthermore, the workshop modeled the use of accurate and inclusive vocabulary and cultural references. It fostered a better understanding of when to choose the right moment to transmit information-for example when responding to a question, in light of a comment, to make connections, or to launch a question to the group. Finally, this workshop, in future iterations, will offer another opportunity to use video; both capsules will be videotaped in order for students to consult them for reference purposes.

\section{Concluding remarks}

While grounding learning in participants' knowledge and experience has been central in adult education and museum learning for decades, a transmission model still appears to have what we would consider to be a firm grip on commonly accepted notions of what a guided visit should entail. Unlearning old habits and assumptions-often based on past learning 
experiences - is an ongoing challenge and is essential to appropriating new ways of being and doing. It is a challenge that requires us to explore the strength of interactive teaching modesdialogue, in particular - through a combination of observation, critical self-reflection, and continual, direct experience in both the role of guide and participant.

Developing and embodying the skills and vocabulary required for facilitating inclusive, engaging dialogue in art museums cannot be acquired overnight and requires a long-term commitment and holistic understanding of the immediate educational and broader socio-political contexts in which guiding occurs. Student-docents need to both understand and accept their role as guides and build the necessary skills and knowledge base. In this pilot project, these factors made the training course both challenging and dynamic, inspiring us to develop innovative learning activities as a result.

\section{References}

Burnham, R., \& Kai-Kee, E. (2011). Teaching in the Art Museum: Interpretation as Experience. Los Angeles, CA: The J. Paul Getty Museum.

Delamatre, J. (2015). Questioning the questioning of questions. Retrieved from http://artmuseumteaching.com/2015/01/23/questioning-the-questioning-of-questions/.

Elbers, E., \& De Haan, M. (2004). Dialogic learning in the multi-ethnic classroom: Cultural resources and modes of collaboration. In J. van den Linden \& P. Renshaw (Eds.), Dialogic Learning (pp. 17-43). Netherlands: Springer.

Flecha, R. (2000). Sharing Words: Theory and Practice of Dialogic Learning. New York: Rowman \& Littlefield Publisher Inc.

Flecha, R., \& Soler, M. (2013). Turning difficulties into possibilities: Engaging Roma families and students in schools through dialogic learning. Cambridge Journal of Education, 
43(4), 451-465.

Frijters, S., Dam, G. T., \& Rijlaarsdam, G. (2008). Effects of dialogic learning on value-laden critical learning. Learning and Instruction, 18(1), 66-82.

Grant, B. (September 28, 2015). Personal communication.

Isaacs, W. N. (1999). Dialogic leadership. The Systems Thinker, 10(1) 1-5.

Lachapelle, R. (in press). The dialogic approach in docent training. Proceedings of the International Society for Education through Art (InSEA) 2014 World Congress held in Melbourne, Australia, July 2014.

Plaza, S. R. (2010). Egalitarian dialogue and instrumental dimension: Two principles of dialogic learning in the classroom. Psychology, Society and Education, 2(1), 61-70.

Renshaw, P. D. (2004). Dialogic learning, teaching and Instruction: Theoretical roots and analytical frameworks. In J. van den Linden \& P. Renshaw (Eds.), Dialogic Learning (pp. 1-15). Netherlands: Springer.

Wegerif, R. (2006). Dialogic education: What it is and why do we need it? Education Review 19(2), 58-66.

\footnotetext{
${ }^{\mathrm{i}}$ In March 2015, Concordia University's School of Extended Learning changed its name to The Centre for Continuing Education.

ii The committee was comprised of the following participants: Jean-Luc Murray, Director of Education and Community Programmes (MMFA), Iris Amizlev, Educational Programmes Officer-Volunteer Guides (MMFA), Brenda Grant, Administrator for Curriculum Development (Concordia), Richard Lachapelle, Professor of Art Education (Concordia).

iii Following an open competition, two of the authors, Emily Keenlyside (M.A. Art Education) and Manon Douesnard (Ph.D. Art Education), were chosen as the instructors of the new docent training course to be offered by Concordia University's School of Extended Learning. iv This is a translation of rencontre, a term adopted by the MMFA to describe what happens in the ideal guided museum visit. The term carries the idea of a get-together among participants instead of the more passive idea of a visit.
} 
${ }^{\mathrm{v}}$ During a presentation in May 2014, Brenda Grant, Administrator, Curriculum Development at Concordia's Centre for Continuing Education presented prospective students with an overview of the Concordia - MMFA partnership.

${ }^{v i}$ Museum educator Jackie Delamatre's recent text is a thoughtful piece on the value of questions in gallery teaching (http://artmuseumteaching.com/2015/01/23/questioning-the-questioning-ofquestions/). 